\title{
Contribuição para o aproveitamento energético do lodo de ETEs em processos térmicos
}

\section{Contribution to the energetic recovery of sludge from WWTP in thermal processes}

Data de entrada: 17/10/2013

Data de aprovação: 30/10/2014

André Pereira Rosa / Carlos Augusto de Lemos Chernicharo / Gilberto Caldeira Bandeira de Melo

DOI: $10.4322 /$ dae. 2014.140

\section{Resumo:}

No Brasil, a principal alternativa para o destino do lodo é o aterro sanitário, o que resulta em elevados gastos com transporte e desperdício do seu potencial energético. Considerando os benefícios referentes à recuperação energética do lodo, os processos térmicos, amplamente empregados para outras fontes de biomassa, têm ganhado destaque, sendo os mais relevantes a pirólise, a gaseificação e a combustão. Esta nota técnica busca contribuir com os estudos de escolha de tecnologias de processamento térmico de lodo, apresentando, de forma comparativa, os diversos aspectos que devem ser considerados.

Palavras-chave: Aproveitamento energético. Lodo. Processos térmicos. Pirólise. Gaseificação. Combustão.

\section{Abstract:}

In Brazil, the main alternative for sludge disposal are the sanitary landfills, resulting in high transportation costs and waste of the sludge energetic potential. Considering the benefits related to the energetic recovery from the sludge, the thermal processes, widely used for other sources of biomass, have been highlighted, being pyrolysis, gasification and combustion the more relevant. This technical note aims to contribute to the studies of selection of alternatives for sludge thermal processing, presenting, in a comparative way, the several aspect that should be considered.

Keywords: Energetic recovery. Sludge. Thermal processes. Pyrolysis. Gasification. Combustion.

\footnotetext{
André Pereira Rosa

\section{Carlos Augusto de Lemos Chernicharo}

\section{Gilberto Caldeira Bandeira de Melo}

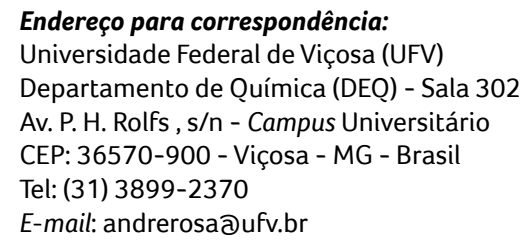

Engenheiro Ambiental pela Universidade Federal de Viçosa (UFV). Doutor e mestre em Saneamento, Meio Ambiente e Recursos Hídricos pela Universidade Federal de Minas Gerais (UFMG). Professor adjunto do curso de Engenharia Química da UFV.

Engenheiro Civil e Sanitarista. Doutor em Engenharia Ambiental pela Universidade de Newcastle Upon Tyne, Reino Unido. Professor Adjunto do Departamento de Engenharia Sanitária e Ambiental da UFMG.

Engenheiro Químico. Mestre em Engenharia Sanitária e Ambiental pela UFMG. Doutor em Ciências de Engenharia pela Universidade de Karlsruhe, Alemanha. Professor associado do Departamento de Engenharia Sanitária e Ambiental da UFMG. 


\section{INTRODUÇÃO}

O gerenciamento do lodo de Estações de Tratamento de Esgoto (ETEs) tem sido um problema de difícil solução nos países industrializados e em desenvolvimento, visto que esse subproduto do tratamento corresponde a uma reduzida parcela do volume de esgoto tratado, enquanto seu manejo pode corresponder a até $50 \%$ dos custos operacionais (SPINOSA et al. 2011). Fernandes et al. (2001) propõem que os estudos de alternativas para gerenciamento e disposição final do lodo devem ser precedidos de estudos das características do esgoto, das tecnologias de tratamento disponíveis, das taxas de produção de lodo, da legislação ambiental e dos tipos de solo e agricultura regional. Apenas após a realização desses estudos é que se deve definir a alternativa de disposição final, devendo esta atender, de forma conjunta, a critérios ambientais, técnicos e econômicos.

Entretanto, observa-se de forma geral que a escolha do gerenciamento do lodo leva em consideração apenas interesses e possibilidades dos seus responsáveis nas unidades de tratamento, não abrangendo, muitas vezes, aspectos ambientais. Entre as principais alternativas para o tratamento do lodo, destacam-se os processos térmicos, nos quais o processamento do lodo ocorre pela destruição química dos polímeros a elevadas temperaturas, sob condições controladas de temperatura, pressão, teor de oxigênio, tempo de reação, entre outros fatores.

Os processos térmicos mais comuns são a pirólise, a gaseificação e a combustão/incineração. A incineração se distingue da combustão por ter como principal objetivo o tratamento de um lodo que não pode ser queimado de forma segura devido à presença efetiva ou potencial de precursores de poluentes não convencionais (especialmente metais e/ou dioxinas e furanos) nas emissões atmosféricas ou nas cinzas, sendo a geração de energia um objetivo secundário. Já a combustão tem como principal finalidade a obtenção de energia pela queima, quando esta puder ser realizada de forma segura sem necessidades especiais de prevenção e/ou controle dos poluentes não convencionais (FYTILI; ZABANIOTOU, 2008). Em todos os tratamentos térmicos, podem-se obter uma expressiva redução do volu$\mathrm{me} / \mathrm{massa}$ de resíduos finais, prevenção de odores e eliminação da biodegradabilidade e do potencial de formação de metano e chorume. Para todos esses processos, o lodo deve ser submetido a etapas prévias de desidratação e/ou secagem (WERLE; WILK, 2010).

De acordo com Werle e Wilk (2010), na Europa, o gerenciamento de lodo de ETE tem como sequência decrescente de prioridades a redução na geração, a minimização, a reciclagem e, por fim, o aproveitamento térmico e envio para aterro sanitário. Atualmente, a alternativa mais empregada no Brasil é o envio do lodo para aterros sanitários. Nesse contexto, destacam-se os elevados gastos na disposição final dos resíduos, além do desperdício do potencial dos nutrientes e/ou energético do lodo desidratado.

Esta nota técnica tem por objetivo apresentar as alternativas e aspectos relativos aos processos térmicos indicados para lodo desidratado com fins de valorização energética, além de contribuir com estudos futuros de processamento térmico de lodo, ainda em expansão no Brasil.

\section{CARACTERÍSTICAS DO LODO DE RELEVÂNCIA ENERGÉTICA}

O lodo de esgoto tipicamente doméstico é uma complexa mistura de substâncias orgânicas e inorgânicas, além de microrganismos. Parte de seus constituintes, como a fração da matéria orgânica (da ordem de 60\%, em base seca), e nutrientes são valorizados para diversos usos, como a aplicação agrícola. Com o objetivo de determinar o potencial de um combustível, faz-se necessário o conhecimento de suas características químicas e térmicas fundamentais, expressas por meio da 
composição elementar, composição imediata e poder calorífico. Na Tabela 1, são apresentados diversos resultados de caracterização de lodos de esgoto, de interesse para estudos de aproveitamento energético. Em linhas gerais, elevados teores de hidrogênio e carbono, assim como re- duzida constituição de água e oxigênio, são fatores que contribuem positivamente com o poder calorífico do lodo (OBERNBERGER et al., 2006). Em relação à composição imediata, elevados teores de carbono fixo apresentam relação direta com o potencial de combustão.

Tabela 1 - Características do lodo desidratado em ETEs, de acordo com diversos autores.

\begin{tabular}{|c|c|c|c|c|c|c|c|c|c|c|c|c|}
\hline \multirow[t]{2}{*}{$\begin{array}{l}\text { Origem do } \\
\text { lodo }\end{array}$} & \multicolumn{5}{|c|}{ Composição elementar (\%), b.s } & \multicolumn{4}{|c|}{ Composição imediata (\%), b.s } & \multicolumn{2}{|c|}{$\begin{array}{c}\text { Potencial } \\
\text { energético } \\
(\mathrm{MJ} . \mathrm{kg}-1), \mathrm{b} . \mathrm{s}\end{array}$} & \multirow[t]{2}{*}{ Fonte } \\
\hline & $\mathrm{C}$ & $\mathrm{H}$ & $\mathrm{N}$ & $\mathrm{S}$ & 0 & SV & SFa & $A$ & w & PCS & $\mathrm{PCl}$ & \\
\hline \multicolumn{13}{|c|}{ Lodo desidratado (seco ou processado termicamente) } \\
\hline LDAn & 36,4 & 5,9 & 5,2 & 1,0 & 19,0 & 59,8 & 7,5 & 32,5 & 6,4 & 17,11 & 13,55 & Arjharn et al. (2013) \\
\hline $\mathrm{LB}+\mathrm{S}$ & 30,2 & 3,7 & 4,3 & 1,0 & 6,4 & 38 & 7,9 & 54,4 & 7,3 & 10,9 & - & Trinh et al. (2013) \\
\hline $\operatorname{LDAn}(\mathrm{LA})+\mathrm{S}$ & $23,1-39,9$ & $3,8-5,9$ & $2,5-7,9$ & $0,8-1,0$ & $18,8-23,5$ & $38,3-66,8$ & $0,9-19,7$ & $22,6-52,0$ & $1,5-7,1$ & - & - & Fonts et al. (2012) \\
\hline $\operatorname{LDAn}(\mathrm{LA})+\mathrm{S}$ & 37,4 & 5,3 & 6,6 & 0,9 & 17,3 & 59,2 & 8,4 & 32,4 & 6,8 & 16,5 & - & Otero et al. (2010) \\
\hline \multirow{3}{*}{$\begin{array}{l}\operatorname{LDAn}(\mathrm{LA}) \\
\quad+\mathrm{S}\end{array}$} & 28,5 & 4,3 & 4,1 & 0,8 & 19,5 & 50,4 & 6,8 & 42,8 & 6,7 & $12,3 c$ & $11,2 c$ & \multirow{3}{*}{ Fonts et al. (2009) } \\
\hline & 23,1 & 3,1 & 3,2 & 0,9 & 14,7 & 40,4 & 4,6 & 54,9 & 5,3 & $8,9 c$ & $8 c$ & \\
\hline & 27,7 & 4,4 & 3,2 & 0,8 & 19,7 & 50,2 & 5,7 & 44,1 & 7,1 & $11,9 c$ & $10,8 \mathrm{c}$ & \\
\hline UASB+LAe & 27,5 & 4,3 & 4,4 & 0,9 & 15,3 & 43,3 & - & 47,6 & 9,1 & 20,1 & 18,6 & Borges (2008) \\
\hline- & 17,4 & 6,7 & 3,8 & - & 20,3 & - & - & 51,8 & 31,7 & - & - & Ginoris (2010) \\
\hline- & 32,8 & 4,5 & 4,4 & 1,7 & 18,9 & - & - & 37,5 & 20 & $9,9 c$ & $8,8 c$ & Faaij et al. (1997) \\
\hline- & 25,6 & 4,4 & 4,6 & 1,1 & 22,0 & - & - & 42,4 & 15 & $14 \mathrm{c}$ & - & Groß (2008) \\
\hline- & 22,7 & 3,3 & 3,1 & 1,6 & 13,3 & 44,5 & & 55,9 & 3,9 & 9,5 & - & Otero et al. (2008) \\
\hline \multicolumn{13}{|c|}{ Lodo desidratado } \\
\hline $\mathrm{LP}$ & $51,5 b$ & $7 b$ & $4,5 b$ & $1,5 b$ & $35,5 b$ & 65 & - & - & - & 15,1 & - & \multirow{2}{*}{$\begin{array}{c}\text { Manara e Zabaniotou } \\
\text { (2012) }\end{array}$} \\
\hline LDAn & $49 b$ & $7,7 b$ & $6,2 b$ & $2,1 b$ & $35 b$ & 50 & - & - & - & 10,8 & - & \\
\hline- & 20,6 & 3,1 & 1,6 & 1,2 & 21,0 & 46,3 & 1,3 & 52,4 & 84,1 & 7,67 & - & Xu et al. (2012) \\
\hline LDAe & 19,8 & 3,6 & 2,1 & - & 20,5 & 42,9 & 3,8 & 53,3 & 58,7 & $8,7 c$ & $2,0 \mathrm{c}$ & Rosa et al. (2011) \\
\hline- & 36,4 & 5,5 & 3,6 & - & 25,5 & 60,1 & 10,9 & 29 & - & 17,5 & - & Courtaud et al. (2010) \\
\hline LDAn (LA) & 29,2 & 4,7 & 2,9 & $<1,0$ & - & - & - & - & 72,8 & 11,5 & - & \multirow{3}{*}{ Font et al. (2001) } \\
\hline LDAn (LA) & 33,6 & 5,1 & 5,4 & $<1,0$ & - & - & - & - & 77,7 & 12,6 & - & \\
\hline LDAn (LA) & 33,6 & 5,2 & 4,2 & $<1,0$ & - & - & - & - & 80,4 & 13,7 & - & \\
\hline LB & 40,8 & 4,4 & 5,7 & 0,0 & 16,8 & 67,6 & - & 32,4 & 65 & 16,5 & $3,5 c$ & \multirow{2}{*}{ Houdkova (2008) } \\
\hline LDAn (LA) & 30,8 & 4,1 & 3,6 & 1,1 & 9,6 & 49,2 & - & 50,8 & 65 & 12,2 & $2,1 c$ & \\
\hline
\end{tabular}

Nota: LDAn: lodo digerido anaerobiamente, LDAe: lodo digerido aerobiamente LA: lodos ativados, LAe: lagoa aerada, S: secagem, LP: lodo primário, LB: lodo bruto. SV: sólidos voláteis, SF: sólidos fixos, A: cinzas, w: umidade, PCS: poder calorífico superior, PCl: poder calorífico inferior, N.d: não detectado, (-) não analisado, b,s: base seca, a: carbono fixo, b: base combustível (livre de cinzas), c: base de trabalho.

Todavia, em estudos de aproveitamento energético de lodos de ETE, torna-se muito importante conhecer também o poder calorífico inferior do lodo, em função dos teores de umidade em que é gerado (b.t), conforme ilustrado na Figura 1, a qual também mostra o $\mathrm{PCl}$ (b.t) de outras fontes de biomassa. Nesse sentido, lodos submetidos a processos térmicos ou de secagem garantem elevados poderes caloríficos, inclusive superiores ao da madeira, como indicado por Faaij et al. (1997) e Fonts et al. (2009). Ainda, lodos com elevados graus de desidratação podem ser considerados fontes potenciais de combustível, conforme resultados de caracterização de lodo de reator UASB, desidratado 
em filtro prensa, reportados por Rosa et al. (2011), que indicaram teor médio de umidade de $58,7 \%$ e PCS e PCl de 8,7 e 2,0 MJ.kg-1 (b.t), respectivamente. Em consonância, Houdkova et al. (2008) obti-

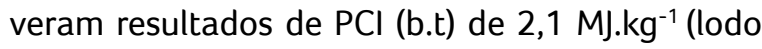

digerido) e 3,5 MJ. $\mathrm{kg}^{-1}$ (lodo bruto), para lodo com umidade de 65,0\%. No entanto, ao comparar o PCl (b.t) com diferentes fontes de biomassa, avalia-se que o lodo apresenta menor potencial de geração de energia para umidade semelhante.

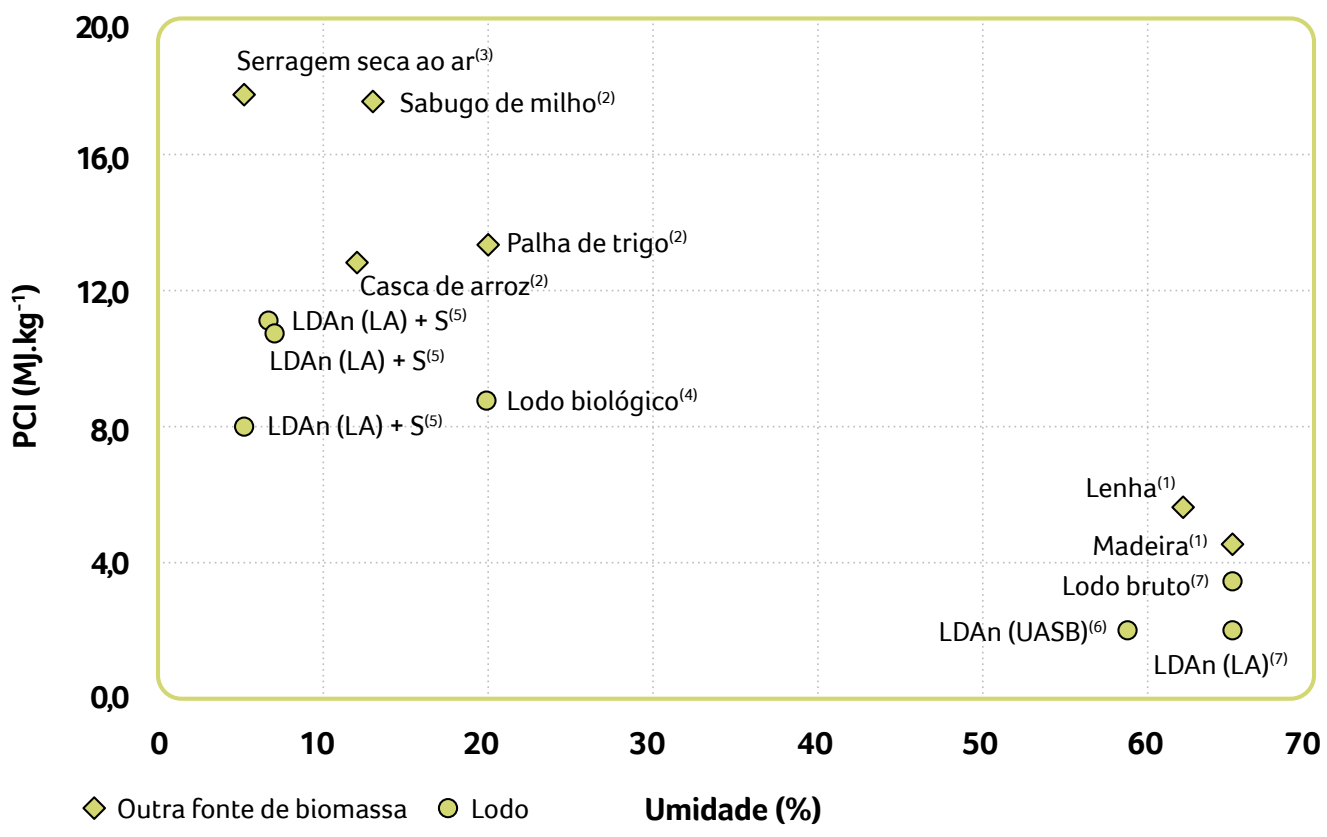

Figura 1 - Poder calorífico inferior de diversas fontes de biomassa, em função da umidade.

Fonte: Adaptado de Faaij et al. (1997), Fonts et al. (2009), Houdkova (2008), Lopes et al. (2001), Nogueira e Lora (2003), Pinheiro et al. (2005) e Rosa et al. (2011). Nota: LDAn: lodo anaeróbio; LA: lodos ativados, S: secagem.

\section{USO DE PROCESSOS TÉRMICOS}

\section{NO GERENCIAMENTO DO LODO}

O lodo de esgoto pode ser considerado uma importante matéria-prima para processos térmicos, como pirólise, gaseificação e combustão, os quais permitem a redução do volume de lodo e a produção de energia para diversos usos (FULLANA et al., 2003; FYTILI; ZABANIOTOU, 2008; TRINH et al., 2013). Esses processos já são amplamente aplicados no tratamento térmico de diversas fontes de biomassa e passam a ser indicados e potencializados para lodo de ETE (FYTILI; ZABANIOTOU, 2008). Destaca-se, ainda, o potencial de uso do lodo no coprocessamento com outras formas de biomassa, possibilitando a redução dos problemas relacionados com elevada umidade e elementos inorgânicos e tóxicos (MANARA; ZABANIOTOU, 2012).

As principais características dos processos térmicos de pirólise, gaseificação e combustão são apresentadas no Quadro 1, enquanto no Quadro 2 são destacadas as vantagens e desvantagens do uso do lodo nesses processos. Observa-se que a fração dos subprodutos gerados está relacionada às condições operacionais, sendo as mais relevantes: pressão, temperatura, umidade e teor de oxigênio. 
Quadro 1 - Comparação dos processos térmicos para lodos de ETEs.

\begin{tabular}{|c|c|c|c|}
\hline Parâmetro de comparação & Pirólise & Gaseificação & Combustão \\
\hline Requerimento de secagem prévia & $\operatorname{Sim}^{1}$ & Sim & Não \\
\hline Temperatura de operação $\left({ }^{\circ} \mathrm{C}\right)$ & $400-800$ & $800-1.400$ & $850-950^{2}$ \\
\hline Pressão para operação & $\begin{array}{l}\text { Ambiente ou ligeiramente inferior/ } \\
\text { superior }{ }^{3}\end{array}$ & Ambiente & Ambiente \\
\hline Condições de reação & Ausência de oxigênio & $\begin{array}{l}\text { Deficiência de oxigênio, possível } \\
\text { adição de água, dióxido de carbono }\end{array}$ & $\mathrm{Ar}$ \\
\hline Subprodutos típicos (\%) & $\begin{array}{c}\text { Gás (até 50), carvão (até 40), óleo } \\
\text { (até 40) }\end{array}$ & $\begin{array}{c}\text { Syngas (até 90), carvão (até 30), } \\
\text { óleo (até 5) }\end{array}$ & $\begin{array}{c}\text { Cinzas (até 30), gases de exaustão } \\
\text { (até 90) }\end{array}$ \\
\hline Produtos gasosos & CH4, H2O, álcoois, aldeídos, fenóis etc. & $\mathrm{CO}, \mathrm{H} 2, \mathrm{CO} 2, \mathrm{CH} 4, \mathrm{H} 2 \mathrm{O}, \mathrm{NO}$ etc. & $\mathrm{N} 2, \mathrm{O} 2, \mathrm{CO} 2, \mathrm{H} 2 \mathrm{O}, \mathrm{SO} 2, \mathrm{NOx}$ etc. \\
\hline Quantidade dos gases produzidos & Variável $^{4}$ & Muito alta & Muito alta \\
\hline Utilidade dos gases & Cogeração & Cogeração & - \\
\hline Utilidade dos líquidos & Cogeração & - & - \\
\hline Utilidade dos sólidos & Cogeração, agricultura & Agricultura & Agricultura \\
\hline
\end{tabular}

Notas: ${ }^{1}$ Requerimento de $150{ }^{\circ} \mathrm{C}$ para um nível de $25 \%$ de sólidos. ${ }^{2}$ Temperatura mínima, a máxima depende de condições de chama.

${ }^{3}$ Depende do principal produto final almejado (vapores ou sólidos). ${ }^{4}$ Depende da pressão e velocidade de aquecimento do substrato (rápida ou lenta).

Quadro 2 - Análise comparativa das principais alternativas de tratamento térmico para lodo de ETE - balanço de vantagens e desvantagens.

\begin{tabular}{|c|c|c|}
\hline Alternativa & Vantagens & Desvantagens \\
\hline Pirólise & $\begin{array}{l}\text { Processo não demanda queima. } \\
\text { Processo flexível e versátil. } \\
\text { Produção de elevada quantidade de óleo, que pode } \\
\text { ser utilizada em vários processos químicos ou cogeração. } \\
\text { Redução de volume do lodo da ordem de } 90 \% \text { e geração } \\
\text { de material inerte. } \\
\text { Exclusão da formação de subprodutos tóxicos (dioxinas), em virtude } \\
\text { da operação em baixas temperaturas e atmosfera redutora. } \\
\text { Formação dos produtos finais (gás, carvão e óleo), os quais apresentam } \\
\text { potencial de serem aproveitados na forma de combustível. } \\
\text { Elevada taxa de conversão dos subprodutos à energia. } \\
\text { Moderado poder calorífico dos gases gerados na pirólise, } \\
\text { da ordem de } 15 \mathrm{MJ} / \mathrm{m}^{3} \text {. }\end{array}$ & $\begin{array}{l}\text { Elevado custo operacional e de manutenção. } \\
\text { Elevado custo de tratamento dos efluentes gasosos e líquidos. } \\
\text { Geração de uma fração sólida que inclui substâncias inertes } \\
\text { e cinzas com potencial concentração dos metais pesados } \\
\text { originalmente presentes no substrato. } \\
\text { Demanda prévia de desidratação e secagem do lodo. } \\
\text { Baixa maturidade tecnológica. } \\
\text { Menor liberação de energia no próprio processo; poder } \\
\text { calorífico continua significativo nos subprodutos. }\end{array}$ \\
\hline Gaseificação & $\begin{array}{l}\text { Produção de energia e redução do volume de resíduos produzidos. } \\
\text { Produção de gás após a gaseificação do lodo com moderada a boa } \\
\text { qualidade e inflamabilidade, o qual pode dar suporte a processos de } \\
\text { secagem do próprio lodo. } \\
\text { Potencial de geração de energia elétrica a partir do gás em } \\
\text { benefício da ETE. } \\
\text { Elevado rendimento na conversão à eletricidade. } \\
\text { Reduzida emissão de poluentes. } \\
\text { Produção de resíduo sólido inerte. }\end{array}$ & $\begin{array}{l}\text { Geração de uma fração sólida que inclui substâncias inertes } \\
\text { e cinzas com elevada constituição de metais pesados. } \\
\text { Demanda prévia de desidratação e secagem do lodo. } \\
\text { Tecnologia complexa e pouco disponível comercialmente. } \\
\text { O alcatrão formado durante o processo de gaseificação, se } \\
\text { não completamente queimado, pode limitar as aplicações } \\
\text { do syngas. }\end{array}$ \\
\hline Combustão & $\begin{array}{l}\text { A cocombustão de lodo e combustível convencional } \\
\text { possui menor investimento. } \\
\text { Recuperação de energia (elétrica e/ou vapor d'água),permitindo a } \\
\text { redução de custos operacionais. } \\
\text { Dispensável, em muitos casos, a secagem do lodo, havendo somente a } \\
\text { necessidade da etapa de desidratação do material. } \\
\text { Elevada redução do volume do lodo, em torno de } 90 \% \text {. } \\
\text { Remoção de praticamente todos os componentes orgânicos. } \\
\text { Possibilidade de utilização das cinzas resultantes do processo. } \\
\text { Alta taxa de liberação do poder calorífico e potencial de } \\
\text { aproveitamento energético. }\end{array}$ & $\begin{array}{l}\text { Custo elevado de implantação e operação. } \\
\text { Geração de uma fração sólida que inclui substâncias inertes e } \\
\text { cinzas com elevada constituição de metais pesados. } \\
\text { Potencial de geração de compostos como } \mathrm{NO}_{x}, \mathrm{SO}_{x^{\prime}} \mathrm{HCl}, \mathrm{HF} \text {, } \\
\text { assim como de metais pesados, dioxinas e furanos. } \\
\text { A combustão direta do lodo pode caracterizar incineração } \\
\text { Demanda prévia de desidratação do lodo. } \\
\text { Elevados custos para o controle ambiental, devido à limpeza } \\
\text { dos gases. }\end{array}$ \\
\hline
\end{tabular}


O processo da combustão é mais difundido e consolidado, apresentando maior simplicidade operacional, menores exigências de preparo do lodo e aplicabilidade a ETEs de diferentes portes. Entretanto, o controle ambiental das unidades que promovem a combustão do lodo deve ser rigoroso, em função do potencial de geração de poluentes, como a dioxina e furanos policlorados, $\mathrm{SO}_{x}, \mathrm{NO}_{x} \mathrm{e}$ metais pesados.

A gaseificação do lodo, quando utilizada para a geração de eletricidade e calor, apresenta compatibilidade técnica e econômica com combustão direta, devido ao uso do gás de síntese (syngas), o qual pode ser aproveitado nas dependências da ETE ou transportado para outras unidades consumidoras adjacentes (fornecimento a longa distância não recomendável, devido à elevada toxicidade do monóxido de carbono, seu principal constituinte).

Assim como a gaseificação, a pirólise requer o preparo do lodo para o processo térmico. É uma alternativa que apresenta flexibilidade no uso dos subprodutos líquidos, sólidos e gasosos, interna e externamente à ETE, assim como o menor potencial de geração de poluentes tóxicos. Esta tecnologia está em crescente desenvolvimento e aplicação prática para fins de aproveitamento energético do lodo.

No Quadro 3, é apresentada uma análise comparativa dos processos térmicos de pirólise, gaseificação e combustão aplicados ao tratamento e aproveitamento energético de lodo de ETE.

Quadro 3 - Análise comparativa de diversos aspectos para o processamento térmico de lodo excedente.

\begin{tabular}{|c|c|c|c|c|}
\hline \multirow{2}{*}{ Aspecto avaliado } & \multirow{2}{*}{ Item } & \multicolumn{3}{|c|}{ Alternativa } \\
\hline & & Pirólise & Gaseificação & Combustão \\
\hline \multirow{2}{*}{ Aspecto econômico } & Custo de instalação (US\$. $\left.\mathrm{kg}^{-1}\right)$ & + & ++ & +++ \\
\hline & Custo de operação/manutenção (US\$. $\mathrm{kg}^{-1}$ ) & +++ & +++ & ++ \\
\hline \multirow{5}{*}{ Aspecto energético ${ }^{2}$} & Energia gerada na forma de calor $\left(\mathrm{MJ} . \mathrm{kg}^{-1}\right)^{1}$ & + & ++ & +++ \\
\hline & Energia gerada na forma de eletricidade $\left(\mathrm{MJ} . \mathrm{kg}^{-1}\right)^{1}$ & + & +++ & ++ \\
\hline & Potencial de geração de subprodutos sólidos & +++ & + & ++ \\
\hline & Potencial de geração de subprodutos líquidos & +++ & ++ & + \\
\hline & Potencial de geração de subprodutos gasosos & + & +++ & ++ \\
\hline \multirow{6}{*}{ Aspecto operacional } & Exigências na preparação/adequação do lodo para aplicação ao processo térmico & + & ++ & +++ \\
\hline & Possibilidade de uso dos subprodutos nas dependências da própria ETE/instalação & +++ & +++ & +++ \\
\hline & Possibilidade de uso dos subprodutos fora das dependências da ETE/instalação & +++ & ++ & + \\
\hline & Necessidade prévia de secagem e adensamento do lodo & ++ & + & +++ \\
\hline & Aproveitamento das cinzas como condicionador de solos & +++ & ++ & + \\
\hline & Redução de volume do material sólido após o processamento térmico (\%) & + & ++ & +++ \\
\hline \multirow{3}{*}{$\begin{array}{l}\text { Aplicação à } \\
\text { realidade brasileira }\end{array}$} & Simplicidade operacional & + & ++ & +++ \\
\hline & Aplicabilidade em ETEs de pequeno porte & + & ++ & +++ \\
\hline & Aplicabilidade em ETEs de médio e grande porte & +++ & +++ & +++ \\
\hline \multirow{3}{*}{$\begin{array}{l}\text { Aspecto relacionado } \\
\text { à pesquisa e } \\
\text { tecnologia }\end{array}$} & Aplicação em escala real para o tratamento térmico de lodo & + & ++ & +++ \\
\hline & Nível de desenvolvimento de pesquisas aplicadas & + & ++ & +++ \\
\hline & Avanço tecnológico e consolidação do estado da arte para o gerenciamento do lodo & + & ++ & +++ \\
\hline \multirow{5}{*}{ Aspecto ambiental ${ }^{2}$} & Potencial de geração de resíduos perigosos & ++ & +++ & ++ \\
\hline & Potencial de geração de efluentes líquidos & + & ++ & +++ \\
\hline & Potencial de emissão atmosférica de dioxinas e furanos & +++ & ++ & + \\
\hline & Potencial de emissão atmosférica de $\mathrm{SO}_{x}$ e $\mathrm{NO}_{x}$ & +++ & ++ & ++ \\
\hline & Potencial de emissão atmosférica de metais pesados & +++ & ++ & + \\
\hline
\end{tabular}

Notas: +++: mais favorável; +: menos favorável; ++: nota intermediária. ${ }^{1}$ Por massa de lodo, em base seca. ${ }^{2}$ No processo térmico em si. 


\section{CONSIDERAÇÕES FINAIS}

Os processos térmicos de pirólise, gaseificação e combustão, até então empregados para outras fontes de biomassa, têm sido considerados alternativas para o gerenciamento de lodo desidratado em ETEs. A combustão, entre os processos, é o precursor; a pirólise e a gaseificação têm sido tema crescente de estudos e pesquisas aplicadas.

Do ponto de vista econômico, a geração de energia elétrica ou calor por meio dos processos térmicos apresenta custos elevados para instalação e operação das plantas, sendo a energia obtida geralmente mais cara do que o consumo de energia provida externamente. Assim sendo, a produção e uso ou exportação de energia (mais cara do que a convencional) somente serão viáveis em um contexto em que houver subsídios pelos benefícios ambientais relacionados à geração de energia de origem renovável, em detrimento do consumo das energias convencionais, e quando os custos considerados para a destinação dos resíduos na situação atual (por exemplo, para dispor em aterros sanitários) internalizarem de forma adequada os custos necessários para implantar e manter aterros com condições adequadas em termos de segurança ambiental, tratamento de gases, chorume etc., permitindo uma comparação econômica equilibrada entre as duas alternativas.

A aplicabilidade dos processos térmicos à realidade brasileira está condicionada à quantidade de lodo gerado e às especificidades locacionais, sendo potencialmente mais vantajosa em ETEs de maior porte, que possuem elevados gastos de transporte e destinação final. Nesse contexto, a combustão apresenta maior avanço tecnológico, além de maior simplicidade operacional e aplicação em ETEs de diferentes portes. Destacam-se a pirólise e a gaseificação como tecnologias que têm sido empregadas e aprimoradas de forma crescente, embora a aplicação em escalas comerciais ainda seja restrita para lodo de ETEs. Entretanto, o controle ambiental das unidades que pro- movem a combustão do lodo deve ser rigoroso, em função do potencial de geração de poluentes, como dioxinas e furanos, $\mathrm{SO}_{x}, \mathrm{NO}_{\mathrm{x}}$ e metais pesados, fator que contribui para os elevados custos de operação e implantação.

$O$ aproveitamento energético do lodo de forma individual ou, até mesmo, em combinação com outros subprodutos gerados em ETEs, a exemplo do biogás, pode garantir a secagem do próprio lodo e favorecer o desenvolvimento e expansão do uso dos processos térmicos para a realidade brasileira.

A crescente expansão dos processos térmicos como alternativas para o gerenciamento do lodo requer, devido à complexidade operacional dos processos, a constante manutenção de equipamentos, a fim de garantir eficiência do sistema de controle ambiental.

\section{REFERÊNCIAS}

ARJHARN, W.; HINSUI, T.; LIPLAP,P.; VIJAYA RAGHAVAN, G.S. Evaluation of an Energy Production System from Sewage Sludge Using a Pilot-Scale Downdraft Gasifier, Energy e Fuels, doi.org/10.1021/ ef3012728, 27, 229-236, 2013.

BORGES, F.; SELLIN, N.; MEDEIROS, S.H.W. Caracterização e avaliação de lodos de efluentes sanitário e industrial como biomassa na geração de energia. Ciência e Energia, v. 17, p. 27 - 32, 2008.

CHUNBAO, C. X.; LANCASTER, J. Treatment of Secondary Sludge for Energy Recovery. In: KÜHTZ, S.; INTINI. F.; BELLINI, S. Energy Recovery Systems from Industrial Plants Waste; Matera: Hardcover. p. 289-310, 2011.

COURTAUD, L; PEREGRINA, C.; CREST, M.; SABLAYROLLES, M.L.; AUDIC, J.M.; ARLABOSSE, P. Alternative fuels derived from organic waste:the case of sewage sludge characterization as a potential energy source. In: 13th INTERNATIONAL SYMPOSIUM ON ENERGY FROM BIOMASS AND WASTE, 2010, Venice, Italy. Proceedings... Italy, 2010.

FAAIJ,A.; VAN REE, R.; WALOHEIML.; OLSON, E.; OUOHUISA.; VANW IJK, A.; DAEY-OUWENCS.; TURKENBERWG. Gasification of biomass wastes and residues for electricity production. Biomass and Bioenergy. v. 12,(6), p.387, 1997.

FERNANDES, F.; LOPES, D.D.; ANDREOLI, C.V.; SILVA, S.M.C.P. Avaliação de alternativas e gerenciamento do lodo na ETE. 2001. 1. ed. Cap. 7, p. 299-317. 
FUNDAÇÃO ESTADUAL DO MEIO AMBIENTE. Aproveitamento energético de resíduos sólidos urbanos: guia de orientação para governos municipais de Minas Gerais/Fundação Estadual do Meio Ambiente - Belo Horizonte:FEAM, 2012. 163p.; il

FONT, R.; FULLANA, A.; CONESA, J. A.; LLAVADOR, F. Analysis of the pyrolysis and combustion of different sewage sludges by TG. Journal of Analytical and Applied Pyrolysis. v. 58-59, p. 927-941, 2001.

FONTS, I.; AZURA, M.; GEA, G.; MURILLO, M.B. Study of the pyrolysis liquids obtained from different sewage sludge. Journal of Analytical and Applied Pyrolysis, v. 85, p. 184-191, 2009.

FONTS, I.; GEA, G.; AZUARA, M.; ÁBREGO, J.; ARAUZO, J. Sewage sludge pyrolysis for liquid production: A review, v. Renewable and Sustainable Energy Reviews, v. 16, p. 2.781-2.805, 2012.

FULLANA, A.; CONESA, J.A.; FONT, R.; MARTI'N-GULLO’N, I. Pyrolysis of sewage sludge: nitrogenated compounds and pretreatment effects. J. Anal. Appl. Pyrolysis, v. 68/69, p. 561_/575, 2003.

FYTILI, D. ZABANIOTOU, A. Utilization of sewage sludge in EU application of old and new methods-A review. Renewable and Sustainable Energy Reviews, v. 12, p.116-140, 2008.

GARCIA, J.; CASTELLS, X. E.; GOYA, J. In: CASTELLS, X. E. Tratamiento y valorización energética de residuos. 2005. Cap. 14, p. $965-$ $1.133,2005$.

GINORIS, Y. P.; GHESTI, G. F.; MALAFAIA, F. R.; BRASIL, A.; MACEDO, J. L.; ITAI, Y. Evaluation of municipal sewage sludge as a biomass resource for the production of energy by gasification. In: 13th INTERNATIONAL SYMPOSIUM ON ENERGY FROM BIOMASS AND WASTE, 2010, Venice, Italy. Proceeding...Italy, 2010.

GROß, B.; EDER, C.; GRZIWA, P.; HORST, J.; KIMMERLE, K. Energy recovery from sewage sludge by means of fluidized bed gasification. Waste Management, v. 28, p.1.819-1.826, 2008.

HOUDKOVA, L.; BORAN, J.; UCEKAJ, V.; ELSASER, T.; STEHLIK, P. Thermal processing of sewage sludge - II. Applied Thermal Engineering. v. 28, p.2.083-2.088, 2008.

JOHNSON, J. E. Formation and reduction of nitrogen oxides in fluidized bed, release and combustion of volatiles. Fuel. v.73, p. 617-26, 1996.

NDAJI, F.E.; ELLYAT, W.A.T.; MALIK, A.A.; THOMAS, K.M. Temperature programmed combustion studies of the co-processing of coal and waste materials. Fuel. v. 78, p.301-307, 1999.

MANARA, P.; ZABANIOTOU, A. Towards sewage sludge based biofuels via thermochemical conversion - A review. Renewable and Sustainable Energy Reviews. v. 16, p.2.566-2.582, 2012.
MONTE, M. C.; FUENTE, E.; NEGRO, A. B. Waste management from pulp and paper production in the European Union. Waste Management, v. 29, p.293-308, 2009.

NOGUEIRA, L.A.H.; LORA, E.E.S. Dendroenergia: fundamentos e aplicações. 2. ed. Rio de Janeiro: Interciência, 2003, 200 p.

OBERNBERGER, I.; BRUNNER, T.; BÄRNTHALER, G. Chemical properties of solid biofuels - significance and impact. Biomass \& Bioenergy, v. 30, p.973-982, 2006.

OTERO, M.; GOMEZ, X.; GARCIA, A. I.; MORAN, A. Non-isothermal thermogravimetric analysis of the combustion of two different carbonaceous materials, Journal of Thermal Analysis and Calorimetry. v. 93, p. 619-626, 2008.

OTERO, M.; SANCHEZ, M.E.; GÓMEZ, X.; MORÁN, A. Thermogravimetric analysis of biowastes during combustion. Waste Management (2010), doi: 10.1016 /j.wasman.2009.12.010.

LOPES, R. P.; SOBRINHO, J. C.; SILVA, J. S.; NOGUEIRA, S. J. FONTES DE ENERGIA PARA SECAGEM DE CAFÉ. Boletim técnico n.3, Universidade Federal de Viçosa, 2001, 29.

PINHEIRO, F. G.; RENDEIRO, G.; PINHO, J. T. Densidade energética de resíduos vegetais. Biomassa e Energia, v. 2, n.2, p. 113-123, 2005.

ROSA, A. P.; LOBATO, L. C. S.; BORGES, J. M.; FONSECA, W. F.; CHERNICHARO, C. A. L. Estimativa do potencial energético de uma estação de tratamento de esgoto doméstico pelo uso dos subprodutos de reatores UASB: lodo excedente e biogás estudo de parâmetros cinéticos do reator UASB. In: $26^{\circ}$ CONGRESSO BRASILEIRO DE ENGENHARIA SANITÁRIA E AMBIENTAL [Anais eletrônico...] Porto Alegre, 2011.

SPINOSA L.; AYOL A.; BAUDEZJ. C.; CANZIANI R.; JENICEK P.; LEONARD A.; Sustainable and innovative solutions for sewage sludge management. Water 2011.v.3, p.702-717, 2011.

TRINH, T. N.; JENSEN, P. A.; JOJHANSEN, K. D.;KNUDSEN, N.O. Influence of the Pyrolysis Temperature on Sewage Sludge Product Distribution, Bio-Oil, and Char Properties. Energy Fuels, v. 27, p. 1419-1427.

WERLE S.; WILK R.K. A review of methods for the thermal utilization of sewage sludge: The Polish perspective. Renewable Energy, doi:10.1016/j.renene.2010.01.019, 2010.

WERTHER, J.; OGADA, T. Sewage sludge combustion. Progress in Energy and Combustion Science, v. 25, p.55-116, 1999.

XU, Z.R.; ZHU, W.; LI, M. Influence of moisture content on the direct gasification of dewatered sludge via supercritical water. International Journal of Hydrogen Energy, v.37, p. 6.527-6.535, 2012. 